\title{
Congenital Subgaleal Cysts over the Anterior Fontanelle in Nigerians
}

\author{
ADELOLA ADELOYE and E. LATUNDE ODEKU \\ From Neurosurgery Unit, Department of Surgery, University of Ibadan, Ibadan, Nigeria
}

\begin{abstract}
Adeloye, A. and Odeku, E. L. (1971). Archives of Disease in Childhood, 46, 95. Congenital subgaleal cysts over the anterior fontanelle in Nigerians. Eighteen cases of a congenital cystic swelling located over the anterior fontanelle are described in Nigerian patients who were otherwise clinically normal, There was a female: male ratio of $2: 1$. Radiologically and at operation, the cysts showed no evidence of intracranial connexion. Excision was curative.

Of 14 cases which were histologically verified, all were dermoid cysts except one in which nerve tissue was present suggesting an encephalocele.

Air cystography was the most useful diagnostic procedure.
\end{abstract}

A congenital midline sincipital cystic swelling of the head inevitably arouses in the clinician's mind the possible existence of some form of meningoencephalocele, or of herniation of brain substance or its enveloping membranes through a defect in the calvarium. Encephalocele of the anterior fontanelle is a rarity, none being found in reported series of encephaloceles from Thailand (Suwanwela and

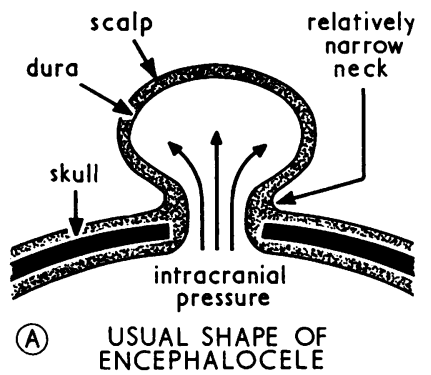

anterior fontanelle and under the galea aponeurotica. It is a soft, fluctuant, non-tender mass which transilluminates, and the edges of the anterior fontanelle may or may not be palpable beyond its broad sessile base (Fig. 2).

Between 1959 and 1969, 18 examples of this peculiar cystic lesion were encountered in Nigerians attending this hospital. In all except 2 cases,

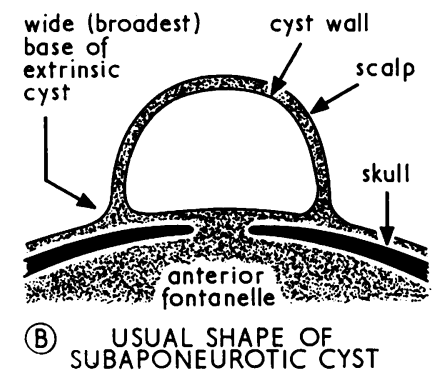

FIG. 1.-Comparative physical characteristics of an encephalocele $(A)$ and a subgaleal (subaponeurotic) cyst (B). (After Odeku, 1967, with courtesy of Ghana Medical Journal.)

Hongsaprabhas, 1966), or Western Nigeria (Odeku, 1967b). We have, however, encountered from time to time an unusual type of congenital cystic lesion situated over the anterior fontanelle. Clinically this cyst resembles an encephalocele (Fig. 1), but there is no evidence, radiological or at operation, of any demonstrable intracranial connexion (Odeku, 1967a). The cyst is solitary and variable in size; it is found in the sincipital region, always over the

Received 23 July 1970. contrast neuro-radiological studies using air were carried out. The nature of the cystic lesion was histologically verified in 14 of the cases.

\section{Clinical Features}

Sex and age incidence. There were 12 females and 6 males, a female predominance of 2:1. All our patients were Nigerians. All presented at hospital in their first year of life, the youngest being $2 \frac{1}{2}$ months old when first seen, except the oldest two who were 13 


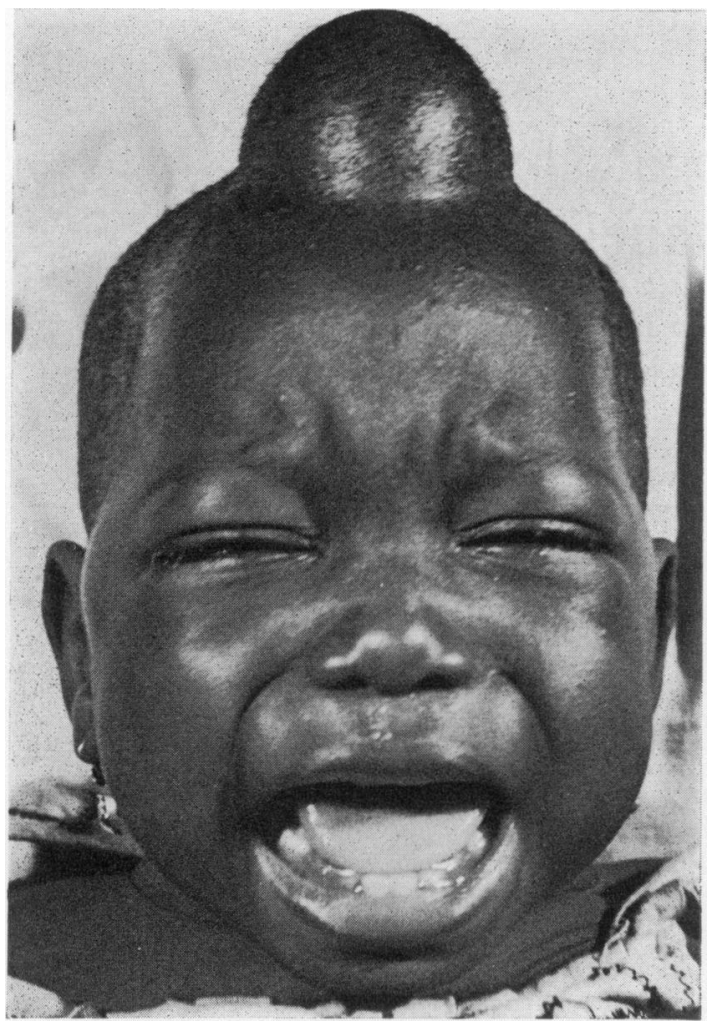

Fig. 2.-Typical appearance of the cyst in a girl of 9 months of age.

months and 18 years (Fig. 3) respectively, when they paid their first visit to this hospital.

Symptomatology. The presenting complaint in every case, was of a swelling on top of the head. It was present at birth in 11 cases, in others it was noted at a postnatal period which varied from 8 days to 7 months. Whatever the time of presentation, they came because the mass was getting bigger. In some it tensed up when the child cried.

There was no family history of a similar lesion. The developmental milestones were all normal.

Physical examination. No abnormality was found apart from the solitary cystic swelling over the anterior fontanelle. The size of the mass varied from $1.3 \mathrm{~cm}$ in diameter to $15 \times 10 \times 6 \mathrm{~cm}$. It was mobile from side to side and from before backwards, and it transilluminated. In 2 cases the mass was pulsatile, and the presence of a bruit over the swelling was recorded in one of these.

Diagnosis. The various initial diagnoses included meningocele (11 cases), encephalocele ( 7 cases), dermoid cyst ( 5 cases), simple inclusion cyst ( 5 cases), sebaceous cyst ( 3 cases), lipoma ( 2 cases), and lymphangioma, haemangioma, cystic hygroma, cephalhaematoma in one case each.

\section{Radiological Features}

Skull $x$-rays revealed only a soft tissue swelling overlying the anterior fontanelle. An open fontanelle was a frequent finding since most of the patients were under the age of 1 ; in older patients, a trough in the outer table of the skull was seen, due presumably to pressure from the cyst.

Air ventriculography and cisternal pneumoencephalography revealed normal ventricular pattern with no extension of the air into the swelling.

Air cystography, where the cyst was aspirated and air injected to replace the fluid, proved a diagnostic procedure. It delineated the sac and showed that there was no escape of air from it into the intracranial cavity, thus confirming the wholly extracranial location of the cyst (Fig. 4).

\section{Fluid Content of Cyst}

The smaller cysts had uniformly clear, colourless fluid, with low protein and sugar content; whereas the larger ones had yellowish fluid with very high protein and sugar content. The aspirate from the smaller cysts tended to be acid in reaction with low sodium and chloride content, and relatively high potassium; whereas that obtained from the larger cysts was alkaline in reaction with high sodium and chloride content and relatively low potassium.

The fluid was bacteriologically sterile.

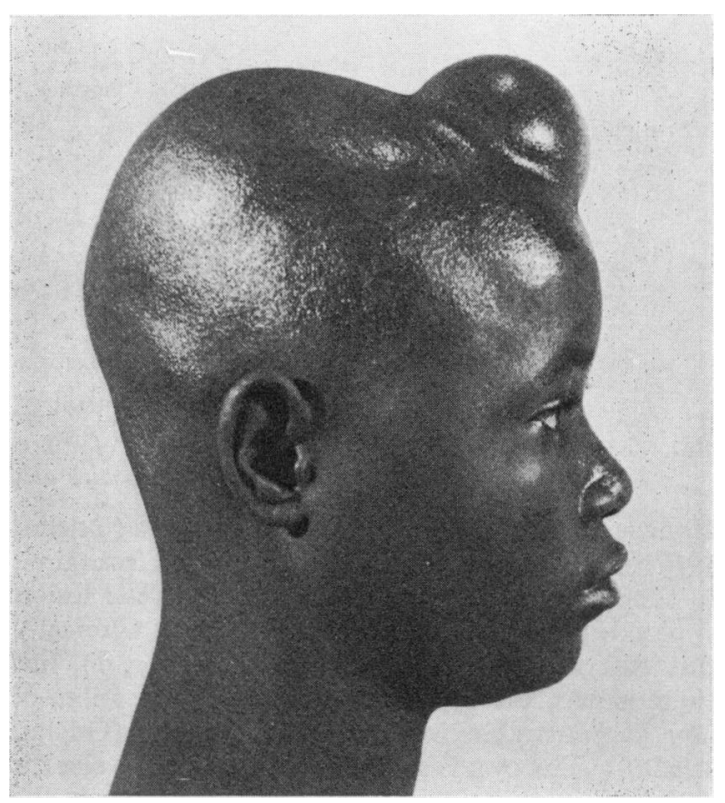

FIG. 3.-The oldcst patient in the series. Cyst was present at birth. 


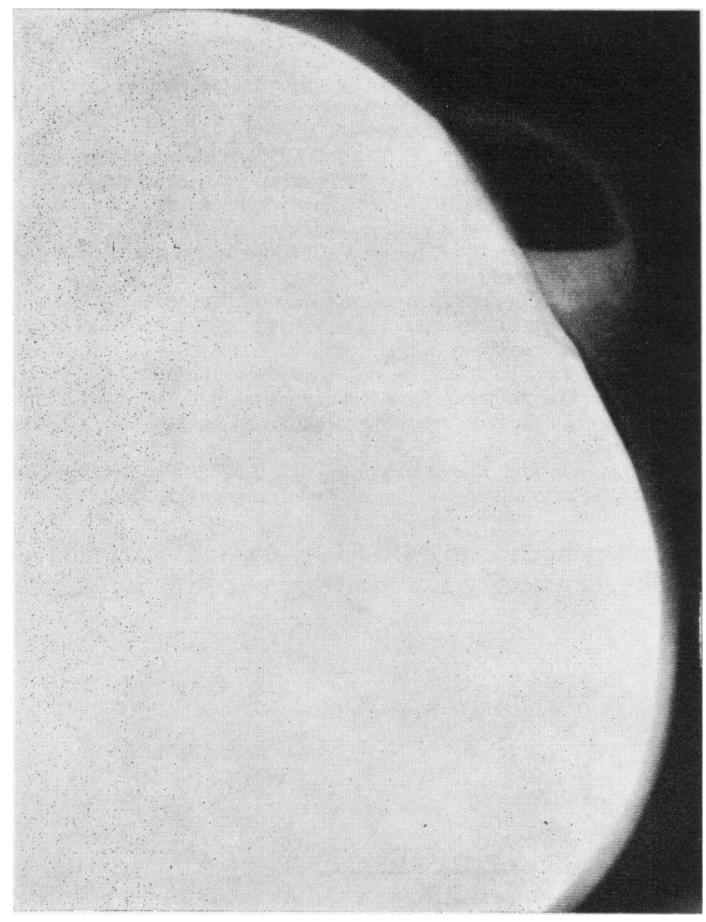

Fig. 4.-Air cystography. Brow up position. Note the inspissated debris below the air in cyst. No intracranial extension of air.

\section{Management}

At present, the treatment of this cyst is surgical excision, after air cystography has confirmed its extracranial location. However, in the past, the policy of management has varied; one case was left untreated because the cyst was getting smaller, and during a period of 6 years the cyst gradually disappeared.

Operative treatment. The cyst is usually blown up with air to facilitate better definition of its extent. An elliptical incision across the summit of the cyst is made, and the cyst shelled out. In all cases, the cyst has been well encapsulated, and without any connexion with the intracranial cavity.

\section{Pathology}

Fourteen of the lesions were histologically verified using haematoxylin and eosin staining. The histological features of 13 of these cases proved to be those of a dermoid cyst. The cyst was lined by attenuated or thin stratified squamous epithelium. The content was predominantly clear fluid admixed with desquamated epithelial cells, sebaceous material, and sometimes hair. Adnexal structuressweat glands, hair follicles, and sebaceous glandswere present in the cyst wall.

The remaining case was different. The cyst was thick walled, and lined by fibrocollagenous tissue and contained no dermal elements, but beneath the fascia aponeurotica, there was an oedematous fibrocellular mass with islands of rudimentary brain tissue. This was therefore probably an encephalocele.

\section{Complications}

These have been remarkably few. Infection was recorded in 3 instances; in 2 cases, this followed aspiration of the cyst or air cystography.

\section{Discussion}

Congenital sincipital cystic lesions over the anterior fontanelle are rare, and, in the few cases described, the nature of the lesions has been variable. Jackson and Thompson (1959) gave a pictorial description of a 'small sessile frontal encephalocele often confused with sebaceous cyst of the scalp' in a child who looked normal as far as could be made out. Ingraham and Matson (1961) illustrated a congenital inclusion cyst in the region of the anterior fontanelle in a boy of 20 months. They labelled it an 'epidermoid'. More recently, Caffey and Silverman (1967) briefly illustrated the case of a 2-year-old patient with a large midline swelling over the frontal bone which was removed surgically. At operation, the skull beneath it was intact and flattened with a bony edge at its margins. No connexion with diploic space or the intracranial cavity was evident. The cyst was a dermoid, as in all except one of our present series.

Dermoids in relation to the cranio-spinal axis have been known since the days of Cruveilhier (1829), but most reports have been confined to those found in the intracranial (Logue and Till, 1952) and intraspinal (Naffziger and Jones, 1935; Boldrey and Elvidge, 1939) cavities. The relatively common occurrence of extracranial dermoids highlighted in this paper contrasts strikingly with the hitherto unknown occurrence of dermoids in the intracranial and intraspinal canal tumours so far encountered in Ibadan Nigerians (Odeku et al., 1970 , to be published).

Though the tendency of dermoid cysts to lie in the midline is well known in general (Bostroem, 1897), as well as among those lying in the posterior fossa (Logue and Till, 1952), we cannot explain why the dermoid cysts in this series were situated regularly over the anterior fontanelle. However, the finding of one case thought to be an encephalocele posed the possibility of an embryological relation between these dermoid cysts and an 
encephalocele which they superficially resemble. If so, the relatively common occurrence of dermoid cysts over the anterior fontanelle may well be the explanation for the virtual absence of encephaloceles at this site in Nigerians.

\section{REFBRENCES}

Boldrey, E. B., and Elvidge, A. R. (1939). Dermoid cysts of the vertebral canal. Annals of Surgery, 110, 273.

Bostroem, E. (1897). Ueber die pialen Epidermoide, Dermoide und Lipome und duralen Dermoide. Zentralblatt für allgemeine Pathologie und Pathologische Anatomie, 8, 1.

Caffey, J., and Silverman, F. N. (1967). Paediatric X-ray Diagnosis, 5th ed., p. 169. Year Book Medical Publishers, Chicago.

Cruveilhier, J. (1829). Anatomie Pathologique du Corps Humain, Vol. 1. Bailliere, Paris.

Ingraham, F. D., and Matson, D. D. (1961). Neurosurgery of Infancy and Childhood. p. 312. C. C. Thomas, Springfield, Illinois.
Jackson, I. J., and Thompson, R. K. (1959). Pediatric Neurosurgery. p. 117. Blackwell, Oxford; C. C. Thomas, Springfield, Illinois.

Logue, V., and Till, K. (1952). Posterior fossa dermoid cysts with special reference to intracranial infection. Fournal of Neurology, Neurosurgery and Psychiatry, 15, 1.

Naffziger, H. G., and Jones, O. W., Jr. (1935). Dermoid tumours of the spinal cord. Report of four cases, with observations on a clinical test for the differentiation of the source of radicular pains. Archives of Neurology and Psychiatry. 33, 941.

Odeku, E. L. (1967a). A massive subaponeurotic 'inclusion' cyst. Ghana Medical fournal, 6, 21.

- (1967b). Congenital malformations of the cerebrospinal axis seen in Western Nigeria. The African child with "encephalocele". International Surgery, 48, 52.

-, Osuntokun, B. O., Adeloye, A., and Williams, A. O. (1970). Tumours of the brain: An African series. Read at the 2nd PanAfrican Congress of Neurological sciences, Ibadan, 1970. To be published.

Suwanwela, C., and Hongsaprabhas, C. (1966). Frontoethmoidal encephalomeningocele. Fournal of Neurosurgery, 25, 172.

Correspondence to Mr. A. Adeloye, Department of Surgery, University College Hospital, Ibadan, Nigeria.

The following articles will appear in future issues of this journal:

Life Tables for Cystic Fibrosis. By L. George and A. P. Norman.

Alkaline Phosphatase for the Detection of Vitamin D Deficiency. By J. M. L. Stephen and P. Stephenson.

Congenital Oligonephronic Renal Hypoplasia with Hypertrophy of Nephrons. By K. J. Van Acker, H. Vincke, J. Quatacker, L. Senesael, and J. van den Brande.

Body Composition from Skinfold Measurements. By C. G. D. Brook.

Breast Milk Jaundice. By T. Hargreaves and R. F. Piper.

Adrenocortical Atrophy and Diffuse Cerebral Sclerosis. By C. C. Forsyth, M. Forbes, and J. N. Cumings. White Cells and Bacteria in Urine of Newborns. By J. M. Littlewood.

Pulmonary Function in Cystic Fibrosis. By S. Godfrey and M. B. Mearns.

Response of Low Birthweight Infants to Treatment with Folic Acid. By W. L. Burland, K. Simpson, and J. Lord.

Blood Phenytoin Estimation in Epilepsy. By K. P. Dawson and A. Jamieson.

Natural History of Spina Bifida Cystica and Cranium Bifidum Cysticum. By K. M. Laurence and B. J. Tew.

Effects on Growth of Antibodies to Human Growth Hormone. By S. R. Chalkley and J. M. Tanner.

Personal Practice: Children Referred for Acute Dialysis. By R. Meadow, J. S. Cameron, C. Ogg, and H. Saxton.

Jejunal Disaccharidase Activities in Marasmus and Kwashiorkor. By W. P. T. James.

Urinary Tract Infection Presenting with Jaundice. By S. H. Ng and J. R. Rawstron.

Malignant Sacrococcygeal Teratoma. By W. G. Scobie.

Insulin Studies in Temporary Neonatal Hyperglycaemia. By M. A. Le Dune.

Radio-isotope Renography as a Renal Function Test in the Newborn. By B. L. Kathel. 